ORIGINAL ARTICLE

\title{
OUTCOME OF OPEN REDUCTION AND INTERNAL FIXATION IN LATERAL CONDYLE HUMERAL FRACTURES IN PEDIATRICS
}

\author{
Khaled M.Hassan, Hosam.M.Khairy, Ahmed.E.El-Malt, Abdul Salam A.Abdul salam* \\ Orthopedic Surgery Department, Faculty of Medicine, Zagazig University, Zagazig, Egypt
}

*Corresponding author: Abdul Salam Alsayid Abdul Salam

Orthopedic Surgery

Department, Faculty of

Medicine, Zagazig University,

Zagazig, Egypt

e-mail:

dr.abdusalamalawamy83@gm ail.com

Submit Date 2019-03-18

Revise Date 2019-04-30

Accept Date 2019-05-06

\begin{abstract}
Background: Lateral condyle fractures of the distal humerus are the second most common fractures at the elbow in the paediatric population usually between the ages of 6-10 years old making up 5-20\% of fractures in children. The aim of the present study was to assess the early results of patients with a displaced lateral humeral condyle fracture treated with open reduction and internal fixation. Methods: Our clinical trial was conducted involving 12 patients treated with open reduction and internal fixation (ORIF). Preoperative stage included clinical evaluation, routine investigations and radiological evaluation. Fractures were classified using the Milch. Patients were followed up weekly until radiological union of the fracture was evident. Results: $83.3 \%$ of our patients were males, while $16.7 \%$ were females. According to mechanism of injury, falling down continues to play a major role in causing disability. At (3-5) weeks all cases were with soft callus remove $\mathrm{K}$ wire; at 8 weeks, all cases were with union fracture; but at 12 weeks, one case $(8.3 \%)$ was with mild stiffness and the rest was with full range of motion. As regards the carrying angle in our study, only $16.7 \%$ were with abnormal carrying angle. $33.3 \%$ were complicated; one case with mild limitation of motion and valgus; one case with varus and two cases with superficial infection. Conclusions: The open reduction and internal fixation of lateral humeral condyle fracture is the ideal treatment and it has a rate of complications.
\end{abstract}

Keywords: Distal humerus, Lateral humeral condyle fracture, open reduction and internal fixation

\section{INTRODUCTION}

\begin{abstract}
A fracture of the distal humerus occurs when there is a fracture anywhere within the distal region (lower end) of the humerus. Lateral condyle fractures of the elbow are the second most common paediatric elbow fracture after supracondylar fractures. They account for 12-20\% of elbow fractures in children. The peak age of incidence is six years. They usually occur as a result of indirect forces being applied to the elbow following a fall on an outstretched hand. Angular and rotational forces are thought to contribute [1].

Non-operative treatment depends on the fracture type. Casting and immobilization can be used for non displaced fractures, particularly with medial, lateral, and
\end{abstract}

supracondylar process fractures (extraarticular and extracapsular) [2].

Distal humerus fractures in children are optimally treated with open anatomic reduction and stable fixation to allow for early anatomic restoration and upper extremity ROM. While operative intervention is not without complications, detailed attention to anatomic reduction, soft-tissue handling and preservation, stable fixation, and early mobilization can reduce complications. For articular fractures and unstable nonarticular fractures, operative treatment with direct visualization of the joint surface and anatomic reduction and stabilization can prevent accelerated arthritis associated with articular incongruity [3]. 
The blood supply of distal humers from the extraosseous circulation receives a rich blood supply, which is organized into three arcades situated medially, laterally, and posteriorly. The medial arcade is formed from the superior collateral, inferior collateral, and posterior recurrent ulnar arteries [4].

This study aims to assess the early results of patients with a displaced lateral humeral condyle fracture treated with open reduction and internal fixation.

\section{METHODS}

The clinical study will be conducted in Orthopedic Surgery Department of Zagazig University Hospitals. Consent was obtained from all parent.

Written informed consent was obtained from all participants and the study was approved by the research ethical committee of Faculty of Medicine, Zagazig University. The work has been carried out in accordance with The Code of Ethics of the World Medical Association IRB 4347/25-2-2018 (Declaration of Helsinki) for studies involving humans.

This study including twelve patients of lateral condyle fracture, 10 male and 2 female their age ranged from minimum 2 years to maximum 8 years.

First group according age: 5 patient both gender(4 male and 1 female)and age range from 2 years to 4.8 years.

Second group according age: 7 patient both gender( 6 male and 1 female)and age range from 5 years to 8 years.

First group according time of operation: 8 ( 7 male and 1 female) before 48 hours from time of trauma.

Second group according time of operation: 4 (3 male and 1 female) after 48 hours from time of trauma.

\section{Inclusion criteria:}

Children with recent lateral humeral condyle fractures, age $<12$ years, patient consent to enter the study and displaced fracture were included.

\section{Exclusion criteria:}

Patients with concurrent supracondylar fractures, fractures $>1$ week, age $>12$ years, open fractures, fracture with neurovascular injury.

\section{Preoperative staging: \\ Patient counseling:}

The followings were discussed with the patients at depth:

The proposed procedure, preoperative investigations, details of operative procedure, Postoperative rehabilitation program and average time of this program, the possible complications, and the anticipated outcome.

\section{Clinical evaluation:}

Each patient in this study was carefully assessed clinically by taking a detailed clinical history and performing a thorough examination.

\section{Routine investigations:}

Complete Blood Count (CBC) and bleeding profile (PT, PTT and INR) were done.

\section{Radiological evaluation:}

Radiological evaluation consisted mainly of plain radiography. Each patient underwent an elbow trauma series which included true anteroposterior view and lateral view.

\section{Preoperative preparation of the patient:}

Preoperative hydration (one liter of Ringer's solution at the morning of operation). One gm antibiotic 1 hour before operation was adminstrated.

\section{Surgical technique:}

Following anaesthetic assessment, all patients with a displaced lateral humeral condyle fracture were consented and listed for ORIF with Kirschner wires (K-wires) in the operating theatre. A single dose of intravenous prophylactic antibiotics was administered at the anaesthetic induction.

The supine position is helpful in order to use the lateral approach to the elbow and tourniquet was used, fluoroscopy (C-arm) in ipsilateral position to fracture.

The lateral approach to the distal humerus, through the interval between brachioradialis and triceps. The joint surface was accurately reduced with minimal dissection of soft tissues from the distal fragment in order to reduce the risk of avascular necrosis of the capitellum.

The reduction was stabilized with two parallel K-wires, under fluoroscopy guide, that were left outside the skin and closure the 
wound layer by layer apply back slab above elbow.

\section{Follow up:}

Patients were followed up weekly until radiological union of the fracture was evident, and thereafter, the wires and the POP were removed in the outpatient department without the use of general or local anaesthetic. Following the removal of plaster, all patients were mobilized with intensive physiotherapy focusing on elbow full range of movement (ROM), mainly with active movement exercises.

\section{Statistical analysis:}

Data collected throughout history, basic clinical examination, laboratory investigations and outcome measures coded, entered and analyzed using Microsoft Excel software. Data were then imported into Statistical Package for the Social Sciences (SPSS version 20.0) (Statistical Package for the Social Sciences) software for analysis. According to the type of data qualitative represent as number and percentage , quantitative continues group represent by mean \pm SD , the following tests were used to test differences for significance; difference and association of qualitative variable by $\mathrm{Chi}$ square test (X2). Differences between quantitative independent groups by $\mathrm{t}$ test, . $\mathrm{P}$ value was set at $<0.05$ for significant results $\&<0.001$ for high significant result.

\section{RESULTS}

Age was distributed as 5 patient under age of $4.8 \mathrm{y}$ and 7 patient above of $4.8 \mathrm{y}$. Age was distributed as $4.83 \pm 1.74$ with minimum 2 and maximum $8 \mathrm{y}$ (figure 1). Male represents majority with $83.3 \%$ (figure 2 ).

$100.0 \%$ were injured by fall down $83.3 \%$ of them were type 2 Milch, only $16.7 \%$ were type $1 \mathrm{Milch}$, no one with associated injury (figure 3 ).

At 3-5 weeks, all studied group were with Soft callus Remove K wire at 8 weeks all studied group were with Union fracture but at 12 weeks $8.3 \%$ ( 1 case) was with mild limition of motion and the rest with Full rang of motion (table 1).

Only $16.7 \%$ were with abnormal carrying angle (one Valgus $8.3 \%$ and one Varus $8.3 \%$ ) comparing with another side (table 2).

$33.3 \%$ were complicated one case with mild limition of motion and valgus one case Varus two with infection (figure 4).

Late intervention was significantly associated with complication (table 3 ).

Table 1. Follow up results among studied group

\begin{tabular}{|c|c|c|c|}
\hline & & N & \% \\
\hline (3-5) weeks & Soft callus Remove K wire & 12 & 100.0 \\
\hline 8 weeks & Union fracture & 12 & 100.0 \\
\hline 12 weeks & Full rang of motion & 11 & 91.7 \\
\hline & Mild limition of motion & 1 & 8.3 \\
\hline & Total & 12 & 100.0 \\
\hline
\end{tabular}

Table 2. Carrying angle distribution among studied group

\begin{tabular}{|c|c|c|c|}
\hline Carrying angle & & $\mathbf{N}$ & $\mathbf{\%}$ \\
\hline & Normal & 10 & 83.3 \\
\hline & Valgus (19 degree) & 1 & 8.35 \\
\hline & Varus (7 degree) & 1 & 8.35 \\
\hline & Total & 12 & 100.0 \\
\hline
\end{tabular}


Table 3. Association with time of intervention

\begin{tabular}{|c|c|c|c|c|c|c|c|}
\hline & \multicolumn{2}{|c|}{ Intervention Time } & \multirow[t]{2}{*}{ Total } & \multirow[t]{2}{*}{$\mathbf{X}^{2}$} & \multirow[t]{2}{*}{$\mathbf{P}$} \\
\hline & & & $<48$ & $>48$ & & & \\
\hline \multirow[t]{4}{*}{ Side } & \multirow[t]{2}{*}{$\mathbf{L t}$} & $\mathbf{N}$ & 5 & 4 & 9 & \multirow[t]{4}{*}{2.0} & \multirow[t]{4}{*}{0.15} \\
\hline & & $\%$ & $62.5 \%$ & $100.0 \%$ & $75.0 \%$ & & \\
\hline & \multirow[t]{2}{*}{$\mathbf{R t}$} & $\mathbf{N}$ & 3 & 0 & 3 & & \\
\hline & & $\%$ & $37.5 \%$ & $0.0 \%$ & $25.0 \%$ & & \\
\hline \multirow{4}{*}{$\begin{array}{l}\text { Type of } \\
\text { fracture }\end{array}$} & \multirow[t]{2}{*}{ Type1 milch } & $\mathbf{N}$ & 1 & 1 & 2 & \multirow[t]{4}{*}{2.89} & \multirow[t]{4}{*}{0.23} \\
\hline & & $\%$ & $12.5 \%$ & $25.0 \%$ & $16.7 \%$ & & \\
\hline & \multirow[t]{2}{*}{ Type2 milch } & $\mathbf{N}$ & 7 & 3 & 10 & & \\
\hline & & $\%$ & $87.5 \%$ & $75.0 \%$ & $83.3 \%$ & & \\
\hline \multirow[t]{4}{*}{ Displacement } & \multirow[t]{2}{*}{$>2 \mathrm{~mm}$} & $\mathbf{N}$ & 7 & 3 & 10 & \multirow[t]{4}{*}{0.3} & \multirow[t]{4}{*}{0.58} \\
\hline & & $\%$ & $87.5 \%$ & $75.0 \%$ & $83.3 \%$ & & \\
\hline & \multirow[t]{2}{*}{$2 \mathrm{~mm}$} & $\mathbf{N}$ & 1 & 1 & 2 & & \\
\hline & & $\%$ & $12.5 \%$ & $25.0 \%$ & $16.7 \%$ & & \\
\hline \multirow[t]{4}{*}{ F12_weeks } & \multirow{2}{*}{$\begin{array}{c}\text { Full rang of } \\
\text { motion }\end{array}$} & $\mathbf{N}$ & 8 & 3 & 11 & \multirow[t]{4}{*}{2.18} & \multirow[t]{4}{*}{0.14} \\
\hline & & $\%$ & $100.0 \%$ & $75.0 \%$ & $91.7 \%$ & & \\
\hline & \multirow[t]{2}{*}{ Mild stiffness } & $\mathbf{N}$ & 0 & 1 & 1 & & \\
\hline & & $\%$ & $0.0 \%$ & $25.0 \%$ & $8.3 \%$ & & \\
\hline \multirow[t]{6}{*}{ Complication } & \multirow[t]{2}{*}{ NO } & $\mathbf{N}$ & 8 & 1 & 9 & \multirow[t]{6}{*}{8.0} & \multirow[t]{6}{*}{$0.018 *$} \\
\hline & & $\%$ & $100.0 \%$ & $25.0 \%$ & $75.0 \%$ & & \\
\hline & \multirow[t]{2}{*}{ Stiffness } & $\mathbf{N}$ & 0 & 1 & 1 & & \\
\hline & & $\%$ & $0.0 \%$ & $25.0 \%$ & $8.3 \%$ & & \\
\hline & Superficial & $\mathbf{N}$ & 0 & 2 & 2 & & \\
\hline & Infection & $\%$ & $0.0 \%$ & $50.0 \%$ & $16.7 \%$ & & \\
\hline Carrying angle & Normal & $\mathbf{N}$ & 7 & 3 & 10 & 2.55 & 0.27 \\
\hline & & $\%$ & $87.5 \%$ & $75.0 \%$ & $83.3 \%$ & & \\
\hline & Valgus & $\mathbf{N}$ & 0 & 1 & 1 & & \\
\hline & & $\%$ & $0.0 \%$ & $25.0 \%$ & $8.3 \%$ & & \\
\hline & Varus & $\mathbf{N}$ & 1 & 0 & 1 & & \\
\hline & & $\%$ & $12.5 \%$ & $0.0 \%$ & $8.3 \%$ & & \\
\hline & & $\mathbf{N}$ & 8 & 4 & 12 & & \\
\hline & & $\%$ & $100.0 \%$ & $100.0 \%$ & $100.0 \%$ & & \\
\hline
\end{tabular}




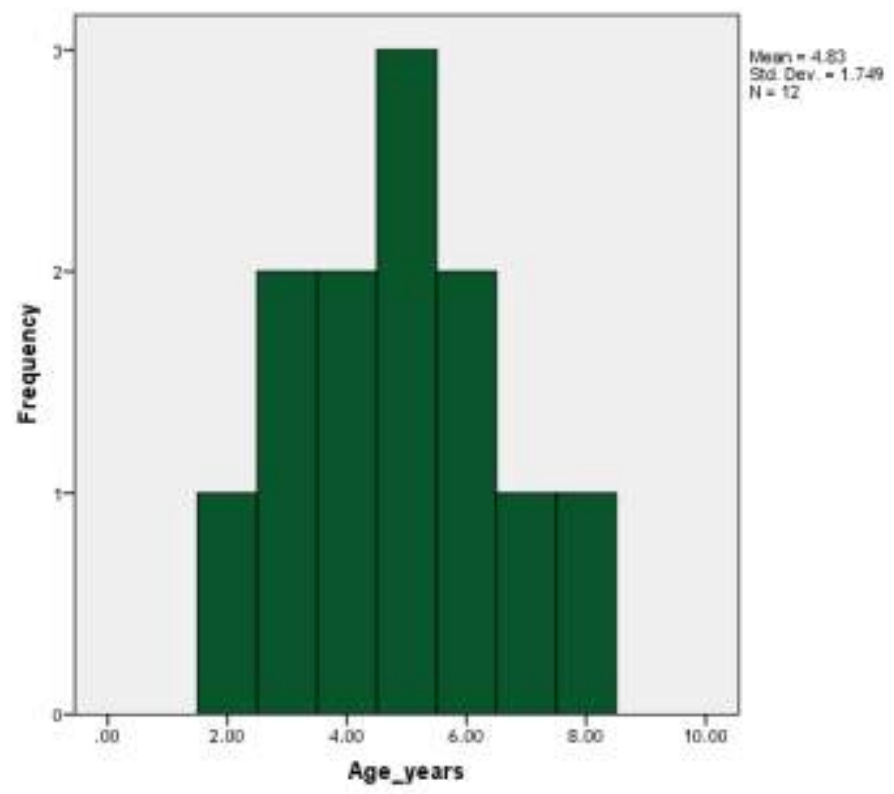

Figure 1. Age distribution among studied group

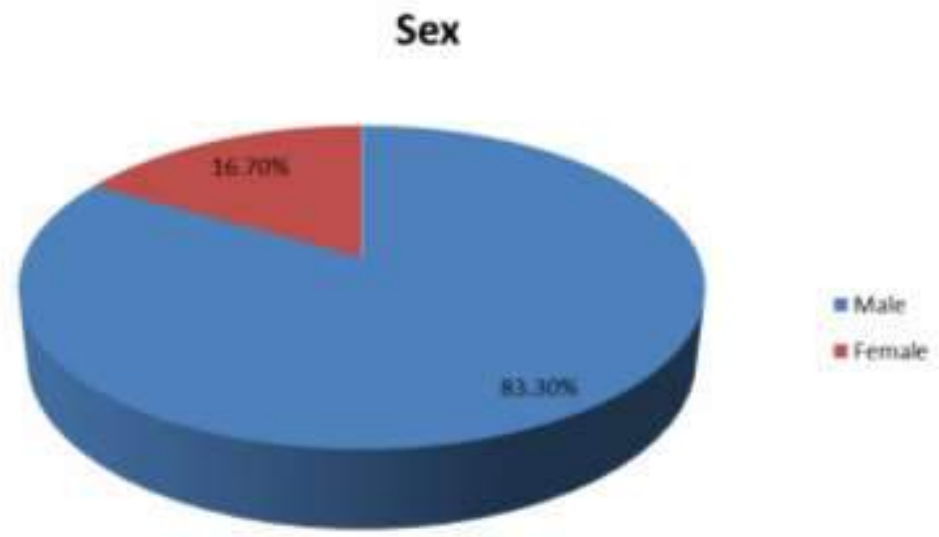

Figure 2. Sex distribution among studied group 


\section{Type of fracture}

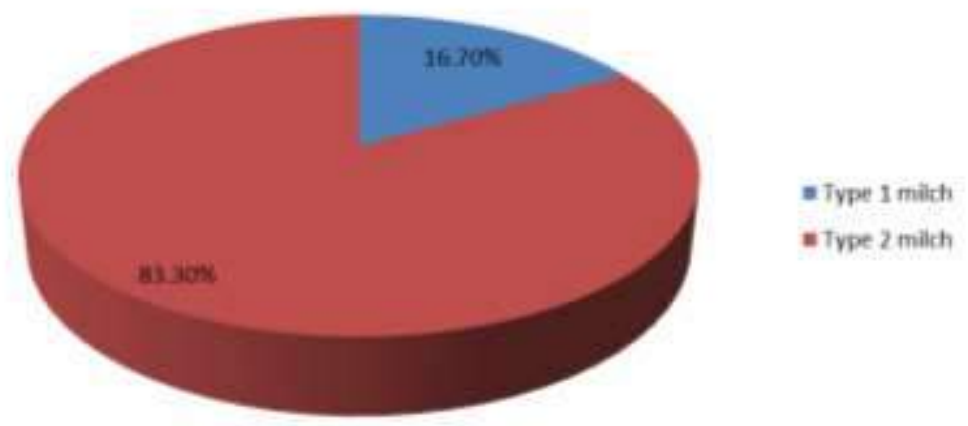

Figure 3. Mechanism and type of fracture

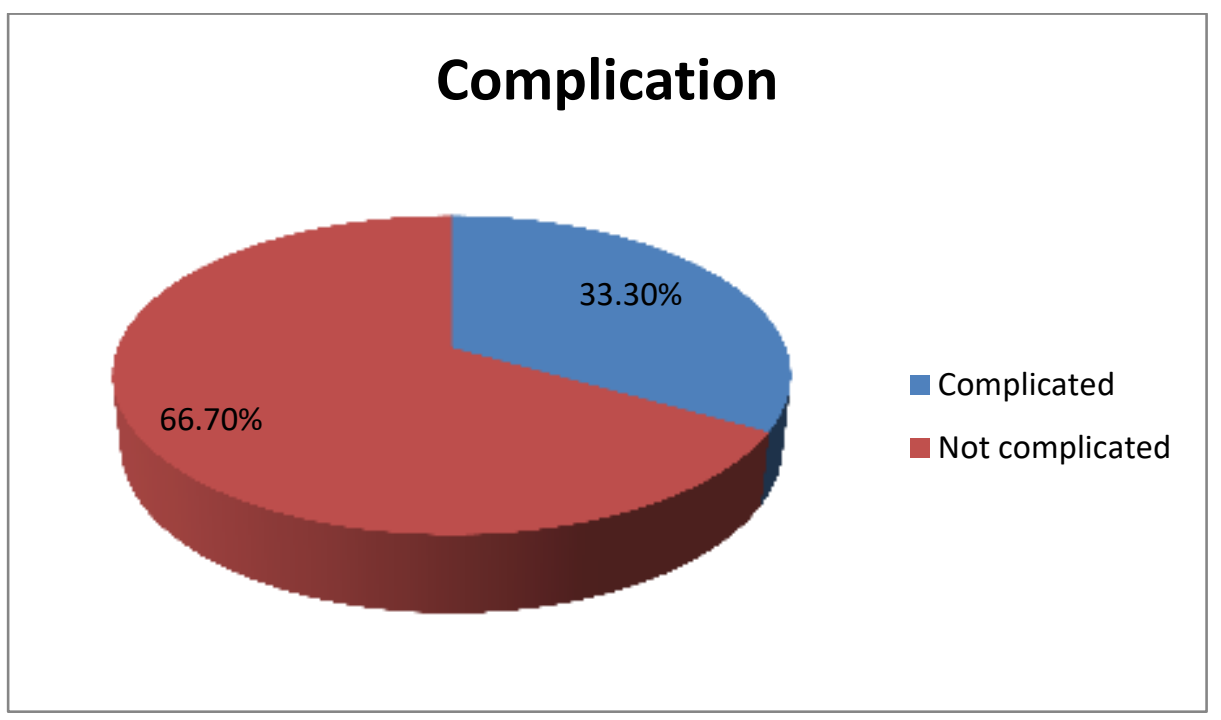

Figure 4. Overall complications

\section{DISCUSSION}

Lateral condyle fractures of the distal humerus are the second most common fractures at the elbow in the paediatric population usually between the ages of $6-10$ years old making up 5-20\% of fractures in children. The diagnosis can be difficult both radiologically and clinically, with loss of function occurring, due to extension into the articular surface. The result of an incorrectly treated lateral condylar physeal injury may not be evident until months or years after the initial index injury [5].

The Milch classification is widely used, and they are; type I and type II according to whether the fracture exited through the capitellar-trochlear groove or through the trochlear, respectively. The Jacob classification dictates whether surgical intervention is required. A Jacob $\mathrm{I}$ is nondisplaced, II is displaced by $2 \mathrm{~mm}$, but not malrotated. Type III is displacement with malrotation [6].

Fractures that are unstable, malrotated and displaced by over $2 \mathrm{~mm}$ usually undergo open reduction internal fixation usually with wires, smooth pins or screws. Debate persists as to how much displacement and fracture instability is required before open reduction and internal fixation (ORIF) is indicated [7].

The aim of the present study was to assess the early results of patients with a displaced lateral humeral condyle fracture treated with open reduction and internal fixation.

Our clinical trial was conducted involving 12 patients treated with open reduction and internal fixation (ORIF). Preoperative stage included clinical 
evaluation (history, general examination and local examination), routine investigations (CBC and bleeding profile) and radiological evaluation (plain radiography). Fractures were classified using the Milch. Patients were followed up weekly until radiological union of the fracture was evident.

In our study, we treated 12 patients divided to two group according age and another two group according time of operation.

According to age: first group from 2 years to 4.8 years 5 (4 male and 1 female), with good result(early callus formation and $\mathrm{K}$ wire removal at 3 weeks, less complication and fall range of motion), while second group from 5 years to 8 years $7(6$ male and 1 female),with result (callus formation and $\mathrm{K}$ wire removal at (4-5weeks),one case with mild limitation range of motion.

According to time of operation after trauma :first group before 48 hours from time of trauma $8(7$ male and 1 female),with excellent reduction, one case with superficial infection (pin tract infection grade 1) and fall range of motion, while second group from 2 day to 7 day 4(3 male and 1 female), with good reduction, one case with superficial infection(pin tract infection grade 2), one case with mild limitation range of motion.

In our study, no significant difference according age of patient, but significant difference according time of operation as early operation as good result and less complication.

With open reduction and internal fixation (ORIF) in a clinical study, Ages of our patients range between 2-8 years with a mean age of 4.83 years. It is demonstrated in our study that $83.3 \%$ of our patients were males, while $16.7 \%$ were females. Leonidou et al. [8] reviewed the results of patients with a displaced lateral humeral condyle fracture treated with open reduction and internal fixation (ORIF). They retrospectively reviewed children treated with ORIF of lateral humeral condyle fractures at a single institution over a period of 13 years. One hundred and five patients with a displaced paediatric lateral humeral condyle fracture were identified and included in the study, 76 males and 29 females. The age of the patients ranged between 3 and 13 years, with a mean of 6.2 years.

According to mechanism of injury, falling down continues to play a major role in causing disability. In our series, it is responsible for all cases; $83.3 \%$ of them were type 2 Milch, only $16.7 \%$ were type 1 Milch and no one with associated injury. In the study done by Leonidou et al. [8], all included cases were the result of low-energy closed injuries. In relation to the Milch's classification, 13 fractures were classified as Milch I and 92 as Milch II.

In our study, at (3-5) weeks all cases were with soft callus remove $\mathrm{K}$ wire; at 8 weeks, all cases were with union fracture; but at 12 weeks, one case $(8.3 \%)$ was with mild stiffness and the rest was with full range of motion. Leonidou et al. [8] found that follow-up ranged between 2 and 8 years with an average of 3.2 years. At the final appointment, all patients had achieved full range of movement of the elbow joint. Furthermore, there were no cases of residual pain, and all patients were happy performing daily life activities and participating in sports. None of the patients in this series developed a non-union or a malunion.

As regards the carrying angle in our study, only $16.7 \%$ were with abnormal carrying angle (one valgus "8.3\%" and one varus "8.3\%").

In our study, $33.3 \%$ were complicated; one case with stiffness and valgus; one case with varus and two cases with superficial infection. There were no significant differences between complicated and noncomplicated cases regarding age, sex, side, type of fracture and displacement. In the study done by Leonidou et al. [8], one patient had a superficial infection around the Kwires, which responded well and eventually resolved with the administration of oral antibiotics. The majority of the fractures demonstrated radiological union between 4 and 6 weeks with the exception of one patient with a Jacob III fracture who reached 8 weeks.

The necessity of reduction and stabilization of displaced and/or rotated lateral condyle fractures has been well established in the literature. However, there are a number of 
controversies in the surgical management of these patients [9].

The first controversy is as to whether displaced and rotated lateral condyle fractures should be managed with ORIF or with CRIF. Advocates of close reduction hypothesize that ORIF might be unnecessary in many cases and that it might even lead to avascular necrosis as a result of extensive soft tissue dissection [10].

Sharma et al. [11] found that in displaced lateral condylar mass fractures of the elbow in children, the surgeon need to be aware of other associated injuries such as elbow dislocation or olecranon fractures.

In a subsequent study, Song et al. [12] prospectively looked at 24 Jacob III lateral condyle fractures. Of these, 18 were managed with CRIF and 6 with ORIF using K-wires. It is of note that out of the 6 cases of ORIF, 3 were the results of the surgeon's lack of confidence and experience.

The vast majority of the cases in both studies by Song et al. [12] were managed by one experienced paediatric orthopaedic surgeon, suggesting that close reduction could work better in the hands of more experienced surgeons.

A second controversy exists as to when the K-wires should be removed. Song and Waters [10] mentioned that displaced fractures should be stabilised until they are healed radiographically. Das De et al. [7] stipulated that leaving the wires exposed following ORIF of a lateral condyle fracture could increase the risk of infection with reported incidences varying from 1 to $28 \%$.

It has been debated whether prophylactic antibiotics should be used for percutaneous wiring of fractures and Subramanian et al. [13] advised against it. Bratzler et al. [14] agreed that prophylactic antibiotics should be used for open orthopaedic procedures where a foreign material is inserted.

Cubitus varus angulation has been a documented complication of lateral condyle fractures. The incidence of cubitus varus is not positively related to either surgical or conservative management. The deformity is most of the times benign and very rarely causes symptoms and requires surgical correction [15].

Nasab and Sabahi [16] assessed the results of treatment of the lateral condylar fractures of the humerus in children. They concluded that open reduction and internal fixation for displaced lateral condyle fracture of the humerus in children with 2-3 k-wire and 2-3 weeks post operative immobilization was associated with a high rate of union and acceptable functional results.

Leonidou et al. [8] demonstrated that fracture union and excellent final outcomes can be expected in all patients, whereby all patients with a displaced fracture are managed by ORIF with K-wire fixation, with the wires only being removed after there is evidence of radiological union.

\section{CONCLUSION}

The open reduction and internal fixation of lateral humeral condyle fracture its the ideal treatment and it has a rate of complications. Our study adds evidence on the outcomes of surgically treated lateral humeral condyle fractures and contributes to the clarification of the associated controversies.

\section{Declaration of interest}

The authors report no conflicts of interest. The authors alone are responsible for the content and writing of the paper.

Funding information:None declared

\section{REFERENCES}

1- Beaty JH, Kasser JR The elbow: Physeal fractures, apophyseal injuries of the distal humerus, avascular necrosis of the trochlea, and T-condylar fractures. In Rockwood and Wilkins' Fractures in Children, $7^{\text {th }}$ Ed. Beaty JH, Kasser JR (Eds). Lippincott Williams \& Wilkins, Philadelphia; (2010): 533-93.

2- Laporte C, Thiongo M, Jegou D Posteromedial approach to the distal humerus for fracture fixation. Acta Orthop Belg; (2006) 72(4):395-9.

3- Chalidis B, Dimitriou C, Papadopoulos P, Giannoudis P. Total elbow arthroplasty for the treatment of insufficient distal humeral fractures. A retrospective clinical study and review of the literature. Injury; (2009) 40(6): 582-90. 
4- Yamaguchi K, Bindra R, Moerry B, Gelberman R. The extraosseous and intraosseous arterial anatomy of the adult elbow. J Bone Joint Surg Am; (1997) 79: 1653-1662.

5- Bauer AS, Bae DS, Brustowicz KA, Waters PM. Intraarticular corrective osteotomy of humeral lateral condyle malunions in children: early clinical and radiographic results. J Pediatr Orthop; (2013) 33(1): 20-25

6- Jakob R, Fowles JV, Rang M, Kassab MT. Observations concerning fractures of the lateral humeral condyle in children. J Bone Joint Surg Br; (1975) 57(4): 430-436.

7- Das De S, Bae DS, Waters PM Displaced humeral lateral condyle fractures in children: should we bury the pins? J Pediatr Orthop; (2012) 32(6): 573-578.

8- Leonidou A, Chettiar K, Graham S, Leonidou O. Open reduction internal fixation of lateral humeral condyle fractures in children: A series of 105 fractures from a single institution. Strat Traum Limb Recon; (2014) 9: 73-78.

9- Song KS, Kang $\mathrm{CH}$, Bae $\mathrm{KC}$, Cho $\mathrm{CH} \&$ Lee JH . Closed reduction and internal fixation of displaced unstable lateral condylar fractures of the humerus in children. J Bone Joint Surge (Am); (2008) 90(12): 2673-2681.

10- Song KS, Waters PM Lateral condylar humerus fractures: which ones should we fix? J Pediatr Orthop; (2012) 32(Suppl 1): S5-S9.
11- Sharma H, Sibinski M, Sherlock DA Outcome of lateral humeral condylar mass fractures in children associated with elbow dislocation or olecranon fracture. Int Orthop; (2009) 33(2): 509-514.

12- Song KS, Shin YW, Oh CW, \& Cho $\mathrm{CH}$. Closed reduction and internal fixation of completely displaced and rotated lateral condyle fractures of the humerus in children. J Orthop Trauma; (2010) 24(7): 434-438.

13- Subramanian P, Kantharuban S, Shilston S, \& Pearce OJ. Complications of Kirschner-wire fixation in distal radius fractures. Tech Hand Upper Extrem Surg; (2012) 16(3): 120-123.

14- Bratzler DW, Dellinger EP, Olsen KM, Perl TM, Auwaerter PG, Bolon MK \& Steinberg JP. Clinical practice guidelines for antimicrobial prophylaxis in surgery. Am J Health Syst Pharm Off J Am Soc Health Syst Pharm; (2013) 70(3): 195-283. 15- Weiss JM, Graves S, Yang S, Mendelsohn E, Kay RM, \& Skaggs DL A new classification system predictive of complications in surgically treated pediatric humeral lateral condyle fractures. J Pediatr Orthop; (2009) 29(6): 602-605.

16- Nasab SAM and Sabahi S Assessment outcome of lateral condylar fractures of distal humerus in children treated by open reduction and internal fixation. Pak $\mathrm{J}$ Med Sci; (2012) 28(4): 617-620. 